\title{
Is Glypican-3 useful Diagnostic Marker that Distinguishes Hepatocellular Carcinoma from Liver Cirrhosis?
}

\author{
Seham A. Omar ${ }^{1}$, Basma Badreldin Hasan ${ }^{2}$. Wael Gamal ${ }^{3}$, \\ Adel Ahmed Hasan ${ }^{4}$ \\ ${ }^{1}$ Internal Medicine Department, Faculty of Medicine, Suez Canal University, Egypt. \\ ${ }^{2}$ Clinical Pathology Department, Faculty of Medicine, Port Said University, Egypt. \\ ${ }^{3}$ Biochemistry Department, Faculty of Medicine, Suez Canal University, Egypt. \\ ${ }^{4}$ Endemic and infectious Diseases Department, Faculty of Medicine, Suez Canal University, Egypt.
}

Corresponding Author Basma Badreldin Hasan

Mobile:

$+201001593877$

E mail:

basmabdr@yahoo.com

Key words:

Glypican-3 (GPC3), HCC (hepatocellular carcinoma), liver cirrhosis, Hcv-related HCC, HCV (hepatitis C virus)
Background and study aim: Glypican-3 (GPC3) is common kind and new type of the Glypicans group. These groups were connected to the epithelial cell membrane by a glycosyl-phosphatidylinositol bond. These proteins control the signaling action of various growth factors, especially Wnts. This reaction is predicated on the power of glypican to initiate, promote or suppress the reaction of these growth agents with their interactive signaling receptors. It is obviously proven and documented that GPC3 is secreted and released by most malignant liver cells, this glypican is not isolated from healthy hepatocyte, cirrhotic liver cells, or in even in benign liver masses. GPC3 accelerates the development of malignant liver lesions especially HCC by stimulating canonical Wnt impulses. The study aimed to characterize and assess the diagnostic accuracy of serum glypican-3 (GPC3) in early detection of $\mathrm{HCC}$ in cirrhotic patients and could be used as good screening marker for $\mathrm{HCC}$ in cirrhotic patients instead of AFP.

Patients and Methods: We enrolled 60 patients which divided into 2 groups, group1 which included 30 patients diagnosed to have $\mathrm{HCC}$ and group 2 which included 30 patients diagnosed to have liver cirrhosis.

Results: Our results revealed increased levels of Glypican-3 in hepatoma group and liver cirrhosis group with no significant difference $(p=0.3)$.

Conclusion: Serum GPC3 is not an efficient immune-marker for $\mathrm{HCC}$ that can be used alone to differentiate $\mathrm{HCC}$ from benign hepatic focal lesions, particularly hepatocellular adenoma.

\section{INTRODUCTION}

Liver cancer is a fatal malignancy and ranking to be the second explanation for malignancy-related mortality, and hepatocellular carcinoma (HCC) is the commonest type [1]. Hepatocellular carcinoma (HCC) is considered to be the 6th most common debilitating malignancy in the world. The incidence of HCC was rising over the last few years all over the world [2]. Meanwhile, its 3rd malignancyrelated death rate among all types of neoplasm denotes the worse outcome. So, the need for molecular targets should be obligatory for surveillance of the malignant hepatic focal lesions and the development of new treatment options [3]
Glypican-3 (GPC3) is an oncofetal proteoglycans and attached to the hepatocyte cell wall. They are normally found in the embryonic hepatocytes but not in the normal mature liver. Glypicans are proteins bonded to glycosaminoglycan groups which connected to the outer membrane by a glycosylphosphatidylinositol bond. GPC3 are responsible of regulation, activation and depletion of various growth factors especially Wnts. This control relies on the power of glypicans to activate or suppress these growth factors and reactions with their receptors [4]. However, many studies showed over expression of these GPC 3 at both the cell and protein 
levels in liver malignancy, and its expression denotes poor outcome. These studies also described the role of GPC3 (glypican3) in HCC growth which is binding to molecules such as Wnt signaling proteins and growth agents. Some researcher used GPC3 as a target for early diagnosis and follow up of the efficacy of the treatment modalities in HCC [5].

Nowadays, many researches revealed that GPC3 can activate the proliferation, migration and adherence of malignant cells by up-regulating autocrine/paracrine canonical Wnt signaling [6].

The aim of this study was the assessment the diagnostic accuracy of serum glypican-3 (GPC3) in early detection of $\mathrm{HCC}$ in cirrhotic patients. The study aimed to correlate the clinical significance of serum GPC3 levels and AFP (alpha-fetoprotein) in the diagnosis of HCC based on the diagnostic criteria as:

\section{Sensitivity،}

2. Specifity, and

3. Positive and negative predictive values.

\section{PATIENTS AND METHODS}

This work was carried out as a cross sectionalAnalytic study. 60 patients were included in this study, selected from outpatient clinic and inpatient department of internal medicine in Suez Canal University Hospitals and divided into two groups: Group1:- HCV related HCC $(n=30)$ and Group2: HCV- cirrhotic patients $(\mathrm{n}=30)$, All patients underwent the following : careful History, meticulous clinical examination, regular laboratory tests including; complete blood picture (CBP), hepatic function tests including:AST (Aspartase transferase), ALT (Alanine transferase), ALP (Alkaline phosphatase), albumin, prothrombine time, total bilirubin and direct bilirubin), viral markers [HBs antigen and HCV antibody], Serum level of alpha fetoprotein, Serum level of Glypican-3, Abdominal ultrasonography and triphasic abdominal CT. All included cases of HCC was diagnosed on the basis of the presence of typical vascular enhancement pattern of liver lesion(s) in contrast enhanced triphasic dynamic CT scan (early enhancement in arterial phase and rapid wash out in venous and portovenous phase) [7]. Barcelona Clinic Liver Cancer (BCLC) staging system was used for staging of malignant hepatic focal lesions. Diagnosis of cirrhosis was based on combined historical, clinical, laboratory and radiological findings. Alpha fetoprotein (AFP) was assessed using Biomerieux Vidas Automated Immunoassay Analyzer. According to Chinese and Asia guideline, the serum AFP below $400 \mu \mathrm{g} / \mathrm{L}$ was considered -ve HCC [8]. Commercially available kit (Catalog No. CSBE11333h (96T), Cusabio biotech co. Ltd, Shanghai, China) was used for measurement of serum Glypican-3. It was measured by a quantitative sandwich enzyme immunoassay technique and obeying steps provided by manufacturer protocol

This used kit for quantitative level of glypican-3 in the sample, adopt purified Human glypican-3 to cover microtitre plate, make solid phase antibody, and then add GP-3 to wells. Glypican3 antibody combined with labeled HRP to form antibody- antigen- enzyme- antibody complex, after washing completely, add TMB substrate solution. TMB substrate solution becomes blue color at HRP enzyme-catalyzed, reaction is ended by the addition of a stop solution and the color change is measured at a wave length 450 $\mathrm{nm}$. Spectrophotometer (Bio-Rad xMark, USA) can be used to measure the optical density.

The concentration of glypican -3 in the sample is measured by comparing the O.D. of the samples to the standard curve. Detection range of the kit is: $50 \mathrm{ng} / \mathrm{L}-1500 \mathrm{ng} / \mathrm{L}$. The level and cut off values of serum GPC3 were determined by Receiver-Operator Characteristic curves (ROC) curve. They were 2SD above the mean of the normal persons.

\section{Statistical Analysis}

The database was established on excel files. Data were imported to SPSS software to process data. Significance of statistical difference was measured by two tests: For character variables: Chi-square test $\left(\mathrm{X}^{2}\right)$, Fisher exact $\mathrm{X}^{2}$ and Yates correction $\mathrm{X}^{2}$. For numerical variables: t-test was used. Results were presented in tables and graphs.

\section{RESULTS}

The studied populations were mostly males representing $82.8 \%$ in HCC group versus $83.33 \%$ in cirrhotic group. The mean age was $56.9 \pm$ 7.27years in HCC group while was $52.89 \pm 9.24$ years in cirrhotic group as shown in table 1

There was higher level of leucocytic count in HCC group than in cirrhotic group $(8.57 \pm 5.69$ 
versus $5.54 \pm 3.08$ cell/c.c) which is statistically significant difference $(\mathrm{p}=0.02)$. There were higher mean values of ALT, AST, total bilirubin and direct bilirubin in HCC group than in cirrhotic group $(\mathrm{p}=0.2)$, but with no statistically significance .

As regard to prothrombin time there were significantly higher mean values of prothrombin time in HCC and cirrhotic groups than in control group ( $\mathrm{p}<0.02)$. Also the study observed that there were statistically significant lower mean values of albumin levels in HCC and in cirrhotic groups $(\mathrm{P}<0.001)$. The rest of the laboratory data as well as their statistical differences between the studied groups are shown in Table 1 .

The mean AFP levels were $2178.47 \pm 3374.8$ and $6.15 \pm 5.9 \mathrm{ng} / \mathrm{ml}$ in $\mathrm{HCC}$, cirrhotic groups respectively with significant statistical difference between HCC versus cirrhotic $(\mathrm{P}=0.001)$. The glypican -3 mean levels were $828.13 \pm 1258.8$ and $1222.86 \pm 1439.7 \mathrm{ng} / \mathrm{ml}$ in $\mathrm{HCC}$ and in cirrhotic group respectively. No significant difference between both study groups regarding serum GPC 3 \&AFP $(p=0.3)$ as showed in table 2 .

S. glypican performed well in detecting the presence of hepatoma in cirrhotic patients; sensitivity and specificity were $62 \%$ and $56.6 \%$ respectively at a cut-off value of $291 \mathrm{ng} / \mathrm{ml}$ as in table4 and figure1. For detection of HCC presence in cirrhotic patients, the sensitivity of AFP was $80 \%$ versus specificity of AFP was $65 \%$ at a cut-off value of $400 \mathrm{ng} / \mathrm{ml}$ in the same settings as shown in figure $1 \& 2$. 
Table (1): Baseline personal and laboratory characteristics among the studied patients.

\begin{tabular}{|c|c|c|c|c|c|c|}
\hline & & \multirow{2}{*}{\multicolumn{2}{|c|}{$\begin{array}{c}\begin{array}{c}\text { HCC group } \\
(\mathbf{n}=\mathbf{3 0})\end{array} \\
56.9 \pm 7.27\end{array}$}} & \multicolumn{2}{|c|}{$\begin{array}{c}\text { Cirrhosis group } \\
(\mathbf{n}=30)\end{array}$} & p-value \\
\hline \multirow{3}{*}{$\begin{array}{l}\text { Age } \\
\text { Sex }\end{array}$} & \multirow{2}{*}{\begin{tabular}{|l} 
Mean \pm SD \\
Male \\
\end{tabular}} & & & \multicolumn{2}{|c|}{$52.89 \pm 9.24$} & $0.07(\mathrm{NS})$ \\
\hline & & 24 & $82.8 \%$ & 25 & $83.33 \%$ & \\
\hline & Female & 6 & $17.2 \%$ & 5 & $16.67 \%$ & 0.8 \\
\hline \multirow{2}{*}{ Residence } & Rural & 14 & $48.28 \%$ & 12 & $41.38 \%$ & \multirow{2}{*}{$0.6(\mathrm{NS})$} \\
\hline & Urban & 16 & $51.72 \%$ & 18 & $58.62 \%$ & \\
\hline Hemoglobin (g/dl) & Mean \pm SD & \multicolumn{2}{|c|}{$9.98 \pm 1.28$} & \multicolumn{2}{|c|}{$9.37 \pm 1.57$} & $0.1(\mathrm{NS})$ \\
\hline WBC $\left(\times 10^{3}\right)$ & Mean \pm SD & \multicolumn{2}{|c|}{$8.57 \pm 5.69$} & \multicolumn{2}{|c|}{$5.54 \pm 3.08$} & $0.02 *$ \\
\hline Platelet $\left(\times 10^{3}\right)$ & Mean \pm SD & \multicolumn{2}{|c|}{$131.38 \pm 74.7$} & \multicolumn{2}{|c|}{$98.66 \pm 61.09$} & $0.07(\mathrm{NS})$ \\
\hline ALT & Mean \pm SD & \multicolumn{2}{|c|}{$59.4 \pm 37.1$} & \multicolumn{2}{|c|}{$49.28 \pm 26.7$} & $0.2(\mathrm{NS})$ \\
\hline AST & Mean \pm SD & \multicolumn{2}{|c|}{$85.4 \pm 65.8$} & \multicolumn{2}{|c|}{$66.83 \pm 42.2$} & $0.2(\mathrm{NS})$ \\
\hline Total bilirubin & Mean \pm SD & \multicolumn{2}{|c|}{$5.39 \pm 5.67$} & \multicolumn{2}{|c|}{$3.49 \pm 4.9$} & $0.2(\mathrm{NS})$ \\
\hline Direct bilirubin & Mean \pm SD & \multicolumn{2}{|c|}{$3.74 \pm 5.06$} & \multicolumn{2}{|c|}{$2.06 \pm 4.75$} & $0.1(\mathrm{NS})$ \\
\hline Albumin & Mean \pm SD & \multicolumn{2}{|c|}{$2.24 \pm 0.48$} & \multicolumn{2}{|c|}{$2.71 \pm 0.54$} & $0.001 *$ \\
\hline PT & Mean \pm SD & \multicolumn{2}{|c|}{$19.53 \pm 4.38$} & \multicolumn{2}{|c|}{$16.24 \pm 4.76$} & $0.02 *$ \\
\hline Creatinine & Mean \pm SD & \multicolumn{2}{|c|}{$1.29 \pm 0.99$} & \multicolumn{2}{|c|}{$\frac{10.24 \pm 4.10}{1.22 \pm 0.7}$} & $0.8(\mathrm{NS})$ \\
\hline
\end{tabular}

NS: no statistically significant difference

*Statistically significant difference

Table (2): $\alpha$ fetoprotein and glypican-3 among the studied patients.

\begin{tabular}{|c|c|c|c|c|}
\hline & & $\begin{array}{c}\text { HCC group } \\
(n=30)\end{array}$ & $\begin{array}{c}\text { Cirrhosis group } \\
(\mathbf{n}=\mathbf{3 0})\end{array}$ & p-value \\
\hline \multirow{3}{*}{$\alpha$-fetoprotein } & Mean \pm SD & $2178.47 \pm 3374.8$ & $6.15 \pm 5.9$ & \multirow{3}{*}{$0.001 *$} \\
\hline & Median (IQR) & $549(159-2000)$ & $4(2.5-5.8)$ & \\
\hline & Range & $3.6-10200$ & $1-22$ & \\
\hline \multirow{3}{*}{ Glypican-3 } & Mean \pm SD & $828.13 \pm 1258.8$ & $1222.86 \pm 1439.7$ & \multirow{3}{*}{$0.3(\mathrm{NS})$} \\
\hline & Median (IQR) & $128(8.1-984)$ & $613(5.2-2065)$ & \\
\hline & Range & $2.8-4149$ & $3.3-4500$ & \\
\hline
\end{tabular}

NS: no statistically significant difference

*Statistically significant difference

Table (3): Serum glypican-3 among the studied patients.

\begin{tabular}{|c|l|c|c|c|c|}
\hline \multirow{2}{*}{} & \multicolumn{2}{|c|}{$\begin{array}{c}\text { HCC group } \\
(\mathbf{n = 3 0})\end{array}$} & \multicolumn{2}{c|}{$\begin{array}{c}\text { Cirrhosis group } \\
(\mathbf{n = 3 0})\end{array}$} \\
\cline { 3 - 6 } \multicolumn{2}{|c|}{} & Male & Female & Male & Female \\
\hline \multirow{4}{*}{ Glypican-3 } & Mean \pm SD & $849.7 \pm 1313.9$ & $724.4 \pm 1071.9$ & $1128.9 \pm 1207.5$ & $1338.55 \pm 1728.3$ \\
\cline { 2 - 6 } & \multirow{2}{*}{ Median (IQR) } & 122.5 & 130 & 961 & 25.8 \\
& & $(8.65-1098)$ & $(8.1-984)$ & $(26.5-1670.5)$ & $(5.2-2986)$ \\
\cline { 2 - 6 } & Range & $3.45-4149$ & $2.8-2497$ & $3.6-4500$ & $3.3-4148$ \\
\hline
\end{tabular}

No significant difference according to sex

No significant correlation between glypican-3 and any other laboratory parameters 


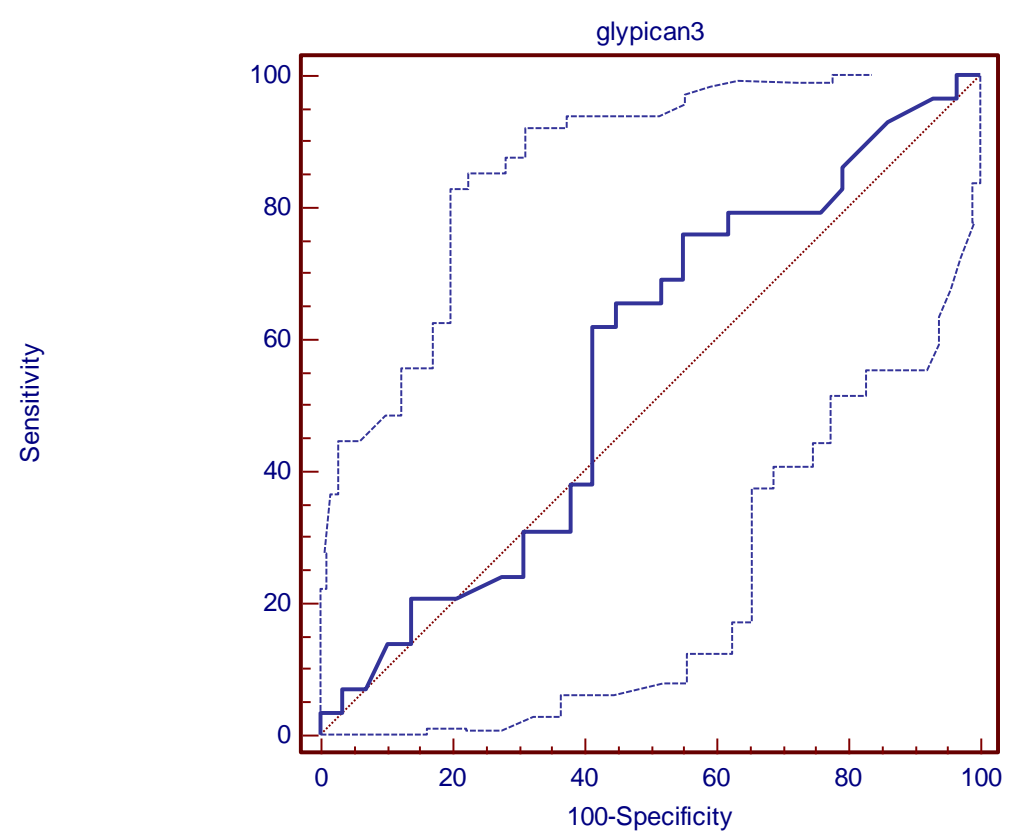

Figure (1): ROC curve for best cutoff values of glypican-3 as marker of HCC.

Area under the curve $=0.56 \quad$ p-value $=0.4(\mathrm{NS})$

Cut off values:

\begin{tabular}{|l|c|c|c|c|c|c|}
\hline Cutoff value & Sensitivity & Specificity & PPV & NPV & $\begin{array}{c}\text { Positive } \\
\text { LR }\end{array}$ & $\begin{array}{c}\text { Negative } \\
\text { LR }\end{array}$ \\
\hline$\leq \mathbf{4}$ & $13.79(4-31.7)$ & $89.66(72.6-97.7)$ & 57.1 & 51 & 1.33 & 0.96 \\
\hline$\leq \mathbf{2 9 1}$ & $62.07(42.3-79.3)$ & $58.62(38.9-76.5)$ & 60 & 60.7 & 1.5 & 0.65 \\
\hline$\leq \mathbf{2 6 8 6}$ & $86.21(68.3-96)$ & $20.69(8-39.7)$ & 52.1 & 60 & 1.09 & 0.67 \\
\hline
\end{tabular}

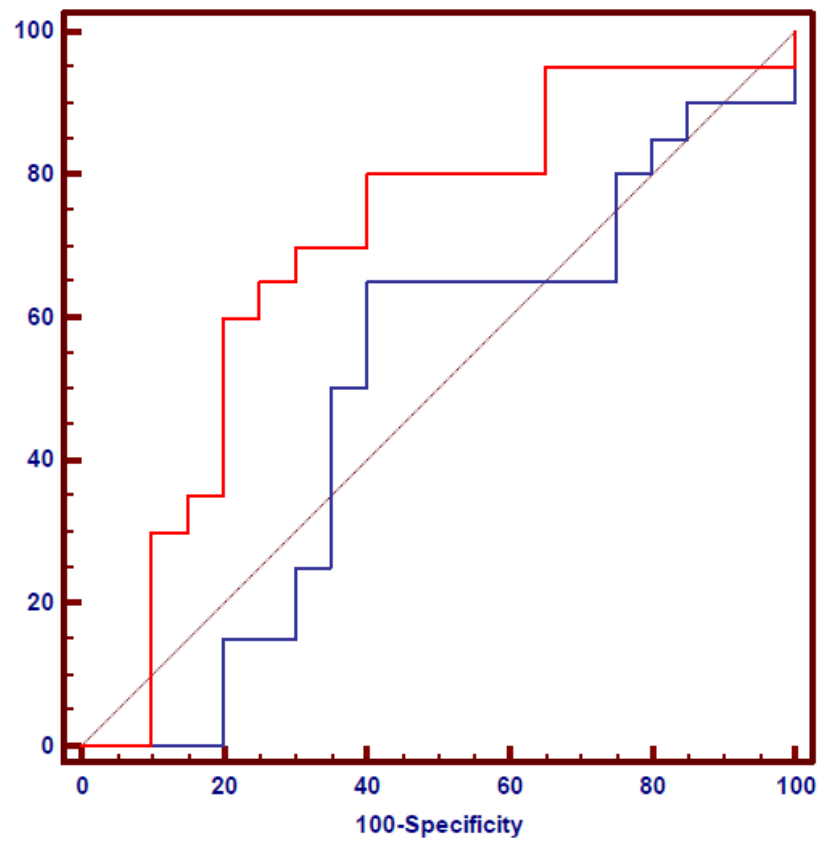

AFP

Glypican-3

Figure (2): Comparing ROC curves of serum glypican-3 (ng/ml) and AFP in diagnosis of HCC among cirrhotic patients $(n=30)$. 


\section{DISCUSSION}

HCC, one amongest the foremost aggressive malignancies, is accompanied by poor outcome despite continuous and significant improvement in operative and loco- ablative treatment options in the last few years [9]. Recently, many researchers were concentrated on the technique of metastasis/recurrence of hepatoma beside the prognosis and Treatment modalities.

Approximately $75 \%$ of $\mathrm{HCC}$ patients came with advanced unresectable disease with severely disturbed liver profile [10]. There is a pressing need for a biomarker that detects the presence of $\mathrm{HCC}$ at a better capacity than AFP.

In this study, $\mathrm{HCC}$ is more presented in males than in females this is in agreement with Abdel-Samee et al. [7] who presented that men are two to three times higher than women, because males are more prone to $\mathrm{HCV}$ infection than females. The same results were reported in Egyptians series by ElZanaty et al. [11]. Table (1).

Similar results about higher prevalence in males than in females were found in a recent African study performed by Ayele and Gebre-Selassie [12]. The study was included 120 patients with chronic HCV infection and divided into 76 males $(63.3 \%)$ and $44(36.7 \%)$ are females (female to male ratio of 1: 1.7 .

We found that the mean age of the HCC group was $56.9 \pm 7.27$ years while the age mean of the cirrhotic group is $52.89 \pm 9.24$ years. This is in harmony with the results Mohamed et al. [13] and his study revealed that the common age group smitten by HCC was between 51 and 60 years as the progress of the disease takes time from hepatitis to cirrhosis to HCC. Table (1).

There were statistically significant low mean values of serum albumin in both HCC and cirrhotic groups being $2.24+0.48 \mathrm{gm} / \mathrm{dl}$ and $2.7+0.54 \mathrm{gm} / \mathrm{dl}$ respectively $(\mathrm{p}=0.001)$. This comes in agreement with Brian et al. [10] who reported that the prevalence of hepatocellular carcinoma is increased in patients with advanced cirrhosis consequently these HCC patients have marked hypoalbuminemia. There were also high levels of serum total bilirubin, direct bilirubin and prothrombin time. This comes in agreement with Brian et al. [10], who reported that HCC patients with elevated serum bilirubin have worse prognosis. Table (1).
Over the last 40 years, all the physicians used to diagnose HCC by AFP assay. The accuracy of HCC diagnosis by using serum AFP is questionable because its predictive value and its sensitivity are limited. (14-16). in current work, When comparing s glypican -3 with AFP we found that the specificity of AFP $(80.0 \%)$ was higher than that of serum glypican-3 (58.6\%). During analysis we found that serum glypican-3 possess a sensitivity $62.07 \%$ at a cutoff level of $>291(\mathrm{pg} / \mathrm{ml}$ ) for HCC presence. The positive predictive value of s. glypican-3 in the present study was 60.0 at a cutoff value of $>291(\mathrm{pg} / \mathrm{ml})$ compared to AFP, which has a positive predictive value of $69.6 \%$ at a cutoff value of $>400 \mathrm{ng} / \mathrm{ml}$ ). The -ve predictive value of s glypican-3 in the present study is $60.7 \%$ at a cutoff value of $>291(\mathrm{pg} / \mathrm{ml})$ as compared to the negative predictive value of AFP, which has a negative predictive value of $69.6 \%$ at a cutoff value of $>12.4(\mathrm{ng} / \mathrm{ml})$. This was in agreement with Ozhan et al (2018) had recently recorded that the sensitivity of GPC3 was $61.33 \%$ and specificity was $41.82 \%$. Also this study showed that the positive predictive value of GPC 3 was $58.97 \%$ in comparison negative predictive values of GPC3 was $44.43 \%$. This study concluded that we cannot use serum GPC3 alone as sensitive marker for detection and prognostic outcome in patients with malignant hepatic focal lesions (1). However, in current work, glypican-3 over expression was found in $77.4 \%$ of patients who had normal serum AFP in and in $81.2 \%$ of patients who had AFP more or equal to $400 \mu \mathrm{g} / \mathrm{L}$ with no statistical significant difference between GPC3L and serum AFP. The area under a ROC curve of GPC $3 S$ was 0.68 in all HCC patients, 0.81 in serum AFP greater or equal to $400 \mu \mathrm{g} / \mathrm{L}$ and 0.64 in patients with normal AFP. Current work recorded that $54.6 \%$ of patients with $\mathrm{HCC}$ have elevated level of GPC3 especially in normal AFP. hence, these current work was hardly recommended that summation of serum AFP and GPC3 may augment the diagnostic accuracy, mainly for early detection of HCC (1) as showed in Figure 2.

\section{CONCLUSION}

Serum Glypican -3 sounds not to be a good biomarker for early detection of malignant HFL and can be used in combination with APF to improve the sensitivity for $\mathrm{HCC}$ diagnosis.

Funding: This research did not receive any specific grant from funding agencies in the public, commercial, or not-for-profit sectors. 
Conflict of interest: Authors declare no conflict of interest.

\section{Ethical consideration:}

Before the initiation of the study, informed consent was obtained from all individuals chosen for the study. The aim and the value of the work were explained to them in a simplified manner. There was no harm being inflicted on them. On the contrary, all would have the benefits of follow-up and the results of the study. The study was approved by the ethics committee of the Faculty of Medicine, Suez Canal University.

\section{REFERENCES}

1. Zhou F, Shang W, Yu X and Tian J. Glypican-3: A promising biomarker for hepatocellular carcinoma diagnosis and treatment. Med Res Rev 2018; 38(2):741767. Doi: 10.1002/med.21455. Epub 2017 Jun 16.

2. Wei-Kai Xiao, Chao-Ying Qi, Dong Chen, Shao-Qiang Li, Shun-Jun Fu, Bao-Gang Peng, et al. Prognostic significance of glypican-3 in hepatocellular carcinoma: a meta-analysis. BMC Cancer 2014; 14:104 doi: 10.1186/1471-2407-14-104.

3. Jemal A, Bray F, Center MM, Ferlay J, Ward E and Forman D. Global cancer statistics. CA Cancer J Clin 2011; 61:69-90.

4. Filmus $\mathbf{J}$ and Capurro $\mathbf{M}$. Glypican-3: a marker and a therapeutic target in hepatocellular carcinoma. FEBS J 2013 May; 280(10):2471-6. Doi: 10.1111/febs. 12126. Epub 2013 Jan 31.

5. Ozkan H, Erdal H, Koçak E, Tutkak H, Karaeren $\mathrm{Z}$,Yakut $\mathrm{M}$, et al. Diagnostic and prognostic role of serum glypican 3 in patients with hepatocellular carcinoma. J Clin Lab Anal 2011; 25(5):350-3. Doi: 10.1002/jcla.20484.

6. Fu SJ, Qi CY, Xiao WK, Li SQ, Beng BG and Liang LJ. Glypican-3 is a potential prognostic biomarker for hepatocellular carcinoma after curative resection. Surgery 2013; 154: 536-544.

7. Abdel-Sameea E, Zakareya T, Metwaly KH, Abdel-Rahman A., Kamal HM and Abdalla WM. Serum soluble CD25 in hepatocellular carcinoma, shall we be able to change the natural history? Journal of Cancer and Tumor International 2017; ISSN: 24547360, Vol.: 5, Issue: 42017.
8. Asia-Pacific Working Party on Prevention of Hepatocellular Carcinoma, author. Prevention of hepatocellular carcinoma in the Asia-Pacific region: consensus statements. J Gastroenterol Hepatol 2010; 25:657-663. [PubMed]

9. Ning S, Bin C, Na H, Peng S, Yi D, Xiang-hua Y et al. Glypican-3, a novel prognostic marker of hepatocellular cancer, is related with postoperative metastasis and recurrence in hepatocellular cancer patients. Mol Biol Rep 2012; 39:351-357. PubMed Abstract Publisher Full Text

10. Brian IC, Vito G, Giannini, Farinati F, Ciccarese F, Rapaccini GL, Marco DM, et al . Association of abnormal plasma bilirubin with aggressive HCC phenotype; PLOS MED 2014; 41(2): 252-258.

11. El-Zanaty F and Way A. Egypt Demographic and Health Survey (2008). Cairo: National Population Council, ElZanaty and Associates, and ORC Macro 2009; p 431.

12. Ayele AG and Gebre-Selassie S. Prevalence and Risk Factors of Hepatitis B and Hepatitis C Virus Infections among Patients with Chronic Liver Diseases in Public Hospitals in Addis Abbaba , Ethiopia. International Scholarly Research Notices 2013; org/10.1155/2013/56382.

13. Mohamed YA, Mumtaz RG, Riome S, Miller D and Abd-Raddad LJ. the epidemiology of hepatitis $\mathrm{C}$ virus in Egypt BMC Infect Dis 2013; 1471-2334.

14. Tan $\mathrm{CH}$, Low $\mathrm{SC}$ and Thng CH. APASL and AASLD Consensus Guidelines on Imaging Diagnosis of Hepatocellular Carcinoma: A Review. Int J Hepatol 2011; 2011:519783. [PMC free article] [PubMed]

15. Baumhoer D, Tornillo L, Stadlmann S, Roncalli M, Diamantis EK and Terracciano LM. Glypican 3 expression in human nonneoplastic, preneoplastic, and neoplastic tissues: a tissue microarray analysis of 4,387 tissue samples. Am J Clin Pathol 2008; 129:899-906. [PubMed]

16. Wang HL, Anatelli F, Zhai J, Adley B, Chuang ST and Yang XJ. Glypican-3 as a Useful Diagnostic Marker That Distinguishes Hepatocellular Carcinoma From Benign Hepatocellular Mass Lesions. Arch Pathol Lab Med 2008; 132:1723-1728. 